\title{
RECENT ADVANCES IN KHAT RESEARCH
}

\author{
PETER KALIX \\ Département de Pharmacologie, Centre Médical Universitaire, CH 1211 Genève 4, Switzerland
}

(Received 10 July 1984)

\begin{abstract}
Khat leaves are widely used as a stimulant in East Africa and the Arabian Peninsula and the effect of the material was formerly believed to be due to its content of norpseudoephedrine. Recently, however, a new alkaloid, cathinone, has been discovered in khat, and this substance was found to be a potent compound with a pharmacological profile closely resembling that of amphetamine. It was also found that cathinone has the same mechanism of action as amphetamine, i.e. that it causes release at physiological catecholamine storage sites. The present report summarizes the pharmacology of cathinone and shows that this alkaloid must be considered to be the main active constituent of khat.
\end{abstract}

\section{INTRODUCTION}

The chewing of leaves of the khat bush (Catha edulis, Celastraceae) has a stimulating effect and causes a certain degree of euphoria. For this reason, khat is widely consumed in the areas where the plant grows, i.e. in certain regions of East Africa and of the Arabian Peninsula. Since only fresh leaves have the desired effect, the khat habit has remained endemic to these areas. However, mainly because of the possibilities of modern transportation, khat is now available to much larger sections of the population, and it is estimated that, at present, each day between five and ten million people chew khat. Many of them tend to compulsive khat consumption and develop psychic dependence on the drug. Furthermore, with the development of international air travel, khat use tends to spread to countries far away from the areas of cultivation, in particular through the movement of emigrants. Thus, cases of khat-induced psychosis have recently been encountered in the United States (Giannini and Castellani, 1982) and in Great Britain (Gough and Cookson, 1984). The medical problems that arise from khat consumption are partly due to its effect on mental health, and partly to the sympathomimetic effects of the drug. Indeed, khat has been recognized to have amphetamine-like effects. Because of this, and because of the serious socio-economic consequences of khat use, the countries affected by the habit have expressed their concern (Recommendations, First International Conference on Khat, 1983) and are now beginning to take steps for reducing the availability of the drug (Proceedings, WHO Intercountry Meeting on Khat, 1983).

The effects of khat have been described centuries ago in the Arabic medical literature, and knowledge of the khat habit came to Europe mainly through the travel accounts of Carsten Niebuhr at the end of the eighteenth century (see Krikorian, 1983). The first attempts to isolate the active principle of khat were made about 100 years ago (Flückiger and Gerock, 1887), but it was Wolfes (1930) who identified norpseudoephedrine in the leaves. Up to about 1960 this substance was generally believed to be the active principle of khat (Winterfeld and Bernsmann, 1960; Alles et al., 1961), although it had already been stated in 1941 by Brücke that the amount of norpseudoephedrine present in khat was insufficient to account for the symptoms produced. In view of this objection, and because of the international problems associated with khat, the Narcotics Laboratory of the United 
Nations reinvestigated the constituents of the plant (Braenden, 1979; Szendrei, 1980). These studies culminated in the isolation, in 1975, of the ceto analogue of norpseudoephedrine (Fig. 1) from khat leaves, and the name
Since the effects of khat had been described earlier as being reminiscent of those of amphetamine (Eddy et al., 1965), (-)cathinone was examined for amphetamine-like effects, with the initial screening being carried out by an<smiles>C[C](N)C(=O)c1ccccc1</smiles><smiles>C[C](N)C(O)c1ccccc1</smiles>
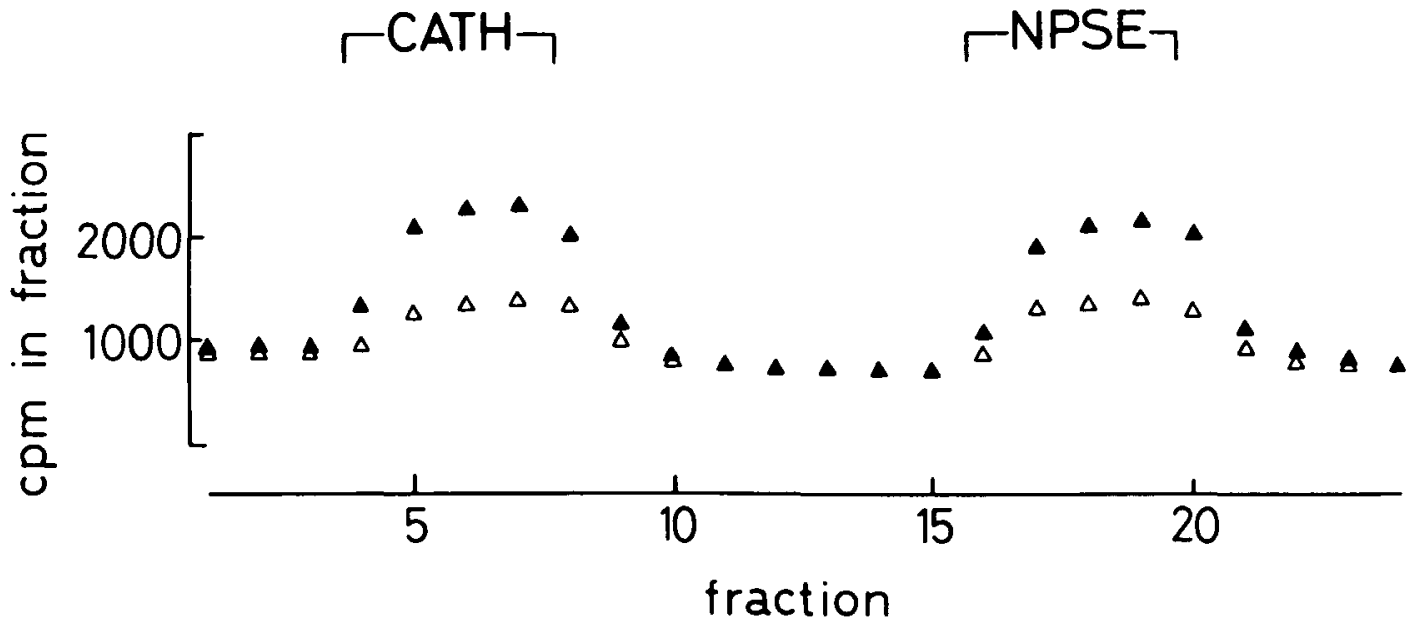

Fig. 1. The effect of $(-)$ cathinone and $(+)$ norpseudoephedrine on the efflux of radioactivity from rat nucleus accumbens tissue prelabelled with ${ }^{3} \mathrm{H}$-dopamine. Two preparations were perfused in parallel and stimulated twice with either $3 \mu \mathrm{M}(-)$ cathinone followed by $24 \mu \mathrm{M}(+)$ norpseudoephedrine $(\Delta)$, or $9 \mu \mathrm{M}(-)$ cathinone followed by $72 \mu \mathrm{M}(+)$ norpseudoephedrine $(\Delta)$. Each fraction corresponds to 3 min of efflux. From Kalix (1983a).

(-)cathinone was suggested for this new alkaloid (UN Document, 1975). Chemically, $(-)$ cathinone bears a close resemblance to amphetamine, the only difference being that the two hydrogens on the first carbon of the amphetamine side chain are substituted by an oxygen. Through further studies (Schorno et al., 1982), it became evident that (-)cathinone is a labile compound that is mainly present in young leaves, and is biodegraded when the leaves start to dry. advisory group of the World Health Organization (1980). When the somatic effects of the new alkaloid were tested, it was found that $(-)$ cathinone, when administered to anaesthetized cats or rats, caused a substantial increase in blood pressure, and that it had a positive inotropic and chronotropic effect in isolated guinea pig heart. Furthermore, constrictions of isolated rabbit ear artery were potentiated by $(-)$ cathinone, whose potency in this respect was similar to that of $(+)$ amphetamine. Taken 
together, these observations suggest that $(-)$ cathinone is responsible for the sympathomimetic syndrome observed after khat consumption.

The behavioural effects observed within the framework of this study are of particular interest, because the effect desired by khat chewers involves CNS stimulation. It has been found that $(-)$ cathinone modifies the locomotor activity of mice in a way analogous to that of $(+)$ amphetamine, and that, in this respect, its potency is similar to that of $(+)$ amphetamine. Furthermore, it was found that, like $(+)$ amphetamine, $(-)$ cathinone was a potent anorectic, that tolerance developed to this effect, and that there was cross-tolerance between the effects of $(-)$ cathinone and (+)amphetamine (Foltin and Schuster, 1982). It was also observed that $(-)$ cathinone maintained the drug-seeking behaviour of rats that had been habituated to (+)amphetamine. Finally, it was shown that in monkeys trained to press a lever for cocaine injections, (-)cathinone elicited rates of responding that were even higher than those obtained with (+)amphetamine. Taken together, these experiments demonstrate that $(-)$ cathinone is a potent amphetamine-like compound and is the constituent of khat that is mainly responsible for the CNS effects. Since (-)cathinone reinforces behaviour of test animals that gives them access to this substance, it can be assumed to be a dependence-producing constituent of khat.

Once the new alkaloid was made available to pharmacologists, the initial studies of the WHO Advisory Group were extended in several directions. For example, the effects of (-)cathinone on some metabolic (Nencini, 1980) and endocrine (Nencini et al., 1983a) parameters, as well as the analgesic properties of the new compound (Nencini and Ahmed, 1982; Nencini et al., 1984) were examined. The cardiovascular effects of $(-)$ cathinone were investigated in anaesthetized dogs and confirmed to be analogous to those of (+)amphetamine (Kohli and Goldberg, 1982). Another group made additional studies on the behavioural effects of $(-)$ cathinone (Foltin and Schuster, 1981, 1982; Johanson and Schuster, 1981) and also studied some neuro- chemical effects. (Wagner et al., 1982). Zelger et al. (1980) showed that rats injected with $(-)$ cathinone displayed the same stereotypical behaviour as that observed after ( + amphetamine administration.

These studies raised the question as to whether (-)cathinone acts by the same mechanism as (+)amphetamine, i.e. through release of neurotransmitter at catecholaminergic synapses. In order to investigate this, experiments were performed in which the effect of the alkaloid on isolated brain tissue pre-incubated with ${ }^{3} \mathrm{H}$-dopamine was examined. When prelabelled slices of rabbit striatum were superfused with solutions of $(-)$ cathinone, a rapid increase of the efflux of radioactivity was observed (Kalix, 1980). Concentrations in the $\mu \mathrm{M}$ range produced this effect, which was found to be dose-dependent and reversible (Kalix, 1981). (+)Norpseudoephedrine had the same effect, but was approximately eight times less potent (Fig. 1). The amphetamine-like releasing effect of $(-)$ cathinone was also demonstrated on tissue from the nucleus accumbens (Kalix, 1982), a brain region thought to be involved in the expression of amphetamine hypermotility (Pijnenburg et al., 1975). It was also shown that substances known to block the releasing effect of $(+)$ amphetamine prevented the induction of release by $(-)$ cathinone (Kalix, $1981,1982)$. Thus, it was concluded that $(-)$ cathinone acts at dopaminergic synapses of the CNS like (+)amphetamine, a view that is now supported by neurochemical (Wagner et al., 1982) and electrophysiological (Mereu et al., 1983) data.

Amphetamine is also known to affect serotoninergic pathways in the CNS (Sloviter et al., 1978) and has been shown to release serotonin from rat corpus striatum in a dose-dependent manner (Azzaro and Rutledge, 1973). In order to determine whether $(-)$ cathinone also mimicks this aspect of amphetamine action, the effect of $(-)$ cathinone on the release of radioactivity from rat striatal tissue prelabelled with ${ }^{3} \mathrm{H}$-serotonin was studied. It was found that a concentration three times higher was needed to produce an effect of an amplitude similar to that produced by a given concentration of $(\dot{+})$ amphetamine (P. Kalix, manuscript 
in press). This means that, with regard to release from CNS serotonin storage sites, $(-)$ cathinone appears to have no greater specificity than $(+)$ amphetamine. There are, however, indications in the literature that the interaction with serotonin pathways might be more important for the action of $(-)$ cathinone than for that of $(+)$ amphetamine (Babayan et al., 1983), possibly because the affinity of $(-)$ cathinone for serotonin receptors is about four times greater than that of (t)amphetamine (Glennon and Liebowitz, 1982).

Since the consumption of khat causes a number of symptoms of the sympathomimetic type, especially at the cardiovascular level, an investigation was made to determine whether these were due to release of noradrenaline from sympathetic nerve endings. Experiments analogous to those on CNS tissue described above were carried out with slices of rabbit heart that had been prelabelled with ${ }^{3} \mathrm{H}$ noradrenaline. It was found that in this tissue superfusion with (-)cathinone caused a substantial increase in the release of radioactivity, and the potency of $(-)$ cathinone was greater than in CNS material (Kalix, 1983a). In heart tissue, as in the CNS, the effect of $(-)$ cathinone was of the same order of magnitude as that of $(+)$ amphetamine, and it could be modified by the same pharmacological manipulations as those of $(+)$ amphetamine (Kalix, 1983b). Surprisingly, (t)norpseudoephedrine was found to be equipotent to $(-)$ cathinone as regards the release from peripheral noradrenaline sites (Kalix, 1983a). Thus, at the cellular level both alkaloids appear to contribute equally to the peripheral effects of khat chewing. In vivo, however, the factor of distribution probably plays an important role, since the greater lipophilicity of $(-)$ cathinone favours its penetration into the CNS. Therefore, it can be assumed that the CNS stimulation resulting from khat chewing is largely due to the (-)cathinone content of the leaves, whereas for the peripheral effects $(+)$ norpseudoephedrine is of an importance at least equal to that of $(-)$ cathinone.

In summary, it can be said that khat is an amphetamine-like plant material, the effects of which can be accounted for by those of the phenethylamines (-)cathinone and, to a lesser extent, $(+)$ norpseudoephedrine. In addition to these two 'khatamines' the leaves also contain the cathedulins (Baxter et al., 1976), an interesting group of substances awaiting pharmacological investigation. The symptoms characterizing drug dependence of the amphetamine type and khat dependence are qualitatively similar. However, long-term use of amphetamine leads to the development of tolerance, which is not apparent for khat (Eddy et al., 1965). This difference may be due to the impossibility of increasing the khat dose beyond a certain limit (Lemordant, 1966). A recent study seems to indicate however, that habitual khat chewers develop a certain degree of tolerance to the sympathomimetic effects of the drug (Nencini et al., 1983b), which suggests that khat resembles amphetamine in this respect too.

Among the recent publications on khat there are also epidemiological studies (Baasher and Sadoun, 1983; Elmi, 1983), one of which analyses the prevalence of khat use in Somalia. Since its appearance, however, the situation in this country has changed profoundly, because the importation and use of khat leaves have been prohibited by government decree. It will be interesting to see the long-term effect of these restrictive measures - an effective ban on khat could have a beneficial effect on public health and alleviate the social problems associated with its use.

\section{REFERENCES}

Alles, G., Fairchild, D. and Jensen, M. (1961) Chemical pharmacology of Catha edulis. Journal of Medicinal and Pharmaceutical Chemistry 3, 323-352.

Azzaro, A. and Rutledge, C. (1973) Selectivity of the release of norepinephrine, dopamine and 5 hydroxytryptamine by amphetamine in various regions of rat brain. Biochemical Pharmacology. 22, 2801-2813.

Baasher, T. and Sadoun, R. (1983) The epidemiology of khat. In Proceedings of the First International Congress on Khat, International Council on Alcohol and Addictions, ed., pp. 161-175, Lausanne.

Babayan, E., Bharkov, N. and Machula, A. (1983) Mediator mechanisms of cathinone effects on animal behaviour. Drug and Alcohol Dependence. 12, 31-35.

Baxter, R., Crombie, L., Simmonds, D. and Whiting, D. (1976) Structures of cathedulin-2 and cathedulin-8, new sesquiterpene alkaloids from Catha edulis. Journal of the Chemical Society: Chemistry Communications 1976, 465-466. 
Braenden, O. (1979) Research on the chemical composition of khat. In Problems of Drug Dependence, NIDA Research Monograph No. 27, pp. 320-321. U.S. Government Printing Office, Washington.

Brücke, F. (1941) Über die zentralerregende Wirkung des Alkaloides Cathin. Archives Experimentalische Pathologie und Pharmakologie 198, 100-106.

Eddy, N., Halbach, H., Isbell, H. and Seevers, M. (1965) Drug dependence: its significance and characteristics. Bulletin of the World Health Organization 32, 721-733.

Elmi, A. (1983) The chewing of khat in Somalia. Journal of Ethnopharmacology 8, 163-176.

Flückiger, F. and Gerock, J. (1887) Contributions to the knowledge of Catha leaves. Pharmaceutical Journal Transactions 18, 221-224.

Foltin, R. and Schuster, C. (1981) The effects of DLcathinone in a gustatory avoidance paradigm. Pharmacology, Biochemistry and Behavior 14, 907-909.

Foltin, R. and Schuster, C. (1982) Behavioural tolerance and cross-tolerance to DL-cathinone and D-amphetamine in rats. Journal of Pharmacology and Experimental Therapeutics 222, 126-131.

Giannini, A. and Castellani, S. (1982) A manic-like psychosis due to khat (Catha edulis). Journal of Toxicology and Clinical Toxicology 19, 455-459.

Glennon, R. and Liebowitz, S. (1982) Serotonin receptor affinity of cathinone and related analogues. Journal of Medicinal Chemistry 25, 393-397.

Gough, S. and Cookson, I. (1984) Khat-induced schizophreniform psychosis in the United Kingdom. Lancet $\mathbf{i}$, 455.

Johanson, C. and Schuster, C. (1981) A comparison of the behavioural effects of L- and DL-cathinone and Damphetamine. Journal of Pharmacology and Experimental Therapeutics 219,. 355-362.

Kalix, P. (1980) A constituent of khat leaves with amphetamine-like releasing properties. European Journal of Pharmacology 68, 213-215.

Kalix, P. (1981) Cathinone, an alkaloid from khat leaves with an amphetamine-like releasing effect. Psychopharmacology 74, 269-270.

Kalix, P. (1982) The amphetamine-like releasing effect of the alkaloid $(-)$ cathinone on rat nucleus accumbens and rabbit caudate nucleus. Progress in Neuropsychopharmacology and Biological Psychiatry 6, 43-49.

Kalix, P. (1983a) A comparison of the catecholamine releasing effect of the khat alkaloids $(-)$ cathinone and (+)norpseudoephedrine. Drug and Alcohol Dependence 11, 395-401.

Kalix, P. (1983b) Effect of the alkaloid (-)cathinone on the release of radioactivity from rabbit atria prelabelled with ${ }^{3} \mathrm{H}$-norepinephrine. Life Sciences 32, 801-807.

Kohli, J. and Goldberg, L. (1982) Cardiovascular effects of $(-)$ cathinone in the anaesthetized dog: Comparison with (+)amphetamine. Journal of Pharmacy and Phar. macology 34, 338-340.

Krikorian, A. (1983) Khat and its use: a historical perspective. In Proceedings of the First International Congress on Khat, International Council on Alcohol and Addictions, ed. pp. 7-71, Lausanne.

Lemordant, D. (1966) Toxicité et antagonistes du Khat. Médecine Tropicale 26, 124-129.

Mereu, G., Pacitti, C. and Argiolas, A. (1983) Effect of $(-)$ cathinone, a khat leaf constituent, on dopaminergic firing and dopamine metabolism in the rat brain. Life Sciences 32, 1383-1389.

Nencini, P. (1980) Cathinone, active principle of the khat leaf: its effects on in vivo and in vitro lipolysis. Pharmacological Research Communications 12, 855861.

Nencini, P., Abdullahi, M., Anania, M., Moscucci, M. and Paroli, E. (1984) Prolonged analgesia induced by cathinone. The role of stress and opioid and non-opioid mechanisms. Pharmacology 29, 269-281.

Nencini, P. and Ahmed, A. (1982) Naloxone-reversible antinociceptive activity of cathinone, the active principle of khat, in mouse and rat. Pharmacological Research Communications 14, 759-770.

Nencini, P., Ahmed, A., Amiconi, G. and Elmi, A. (1983b) Tolerance develops to sympathetic effects of khat in humans. Pharmacology 28, 150-154.

Nencini, P., Anania, M., Abdullahi, M., Amiconi, G. and Elmi, A. (1983a) Physiological and neuroendocrine effects of khat in man. In Proceedings of the First International Congress on Khat, International Council on Alcohol and Addictions, ed. pp. 148-152. Lausanne.

Pijnenburg, A., Honig, W. and Van Rossum, J. (1975) Inhibition of amphetamine-induced locomotor activity by injection of haloperidol into the nucleus accumbens of the rat. Psychopharmacology 41, 87-95.

Proceedings, World Health Organization Meeting on Health, Social and Economic aspects of Khat use (1983) WHO Eastern Mediterranean Office, ed. Alexandria, Egypt.

Recommendations, First International Conference on Khat (1983) International Council of Alcohol and Addictions, ed. Lausanne.

Schorno, X., Brenneisen, R. and Steinegger, E. (1982) Qualitative und quantitative Untersuchungen über das Vorkommen ZNS-aktiver Phenylpropylamine in Handelsdrogen und über deren Verteilung in verschiedenen Organen von Catha edulis. Pharmaceutica Acta Helveticae 57, 168-176.

Sloviter, R., Drust, E. and Connor, J. (1978) Evidence that serotonin mediates some behavioural effects of amphetamine. Journal of Pharmacology and Experimental Therapeutics 206, 348-352.

Szendrei, K. (1980) The chemistry of khat. Bulletin on Narcotics 32, 5-36.

United Nations Document MNAR/11 (1975) Etude sur la composition chimique du khat; recherches sur la fraction phénylalkylamine.

Wagner, G., Preston, K., Ricaurte, G., Schuster, C. and Seiden, L. (1982) Neurochemical similarities between $d$, l-cathinone and $d$-amphetamine. Drug and Alcohol Dependence 9, 279-284.

WHO Advisory Group (1980) Review of the pharmacology of khat. Bulletin on Narcotics 32, 83-93.

Winterfeld, K. and Bernsmann, G. (1960) Zur Kenntnis der Inhaltsstoffe von Catha edulis. Archiv der Pharmazie 63, 991-1000.

Wolfes, O. (1930) Über das Vorkommen von D-nor-isoEphedrin in Catha edulis. Archiv der Pharmazie 268, 81-83.

Zelger, J., Schorno, H. and Carlini, E. (1980) Behavioural effects of cathinone, an amine obtained from Catha edulis: comparisons with amphetamine, norpseudoephedrine, apomorphine and nomifensine. Bulletin on Narcotics 32, 67-81. 